\title{
EVALUATING PERFORMANCE OF CENTRIFUGAL PUMP THROUGH CFD WHILE MODIFYING THE SUCTION SIDE FOR EASTING DISCHARGE
}

\author{
Vibha P.Pode ${ }^{1}$, Shylesha Channapattanna ${ }^{2}$ \\ ${ }^{1}$ Lecturer, Dr.D.Y.Patil Institute of Engineering and Technology,Ambi,Talegaon,Pune, India \\ 2 Asst. Professor,JSPM'S Rajarshi Shahu College of Engineering , Pune, India
}

\begin{abstract}
For operating the pump there are many factor affect pump working which include their speed, suction head, exhaust head, properties of liquid, and physical arrangement etc. cavitations, vibration, reduced efficiency, and lowered capacity could cause serious trouble like Suction Head available, Excessive suction lift, shallow inlet submergence. Category of connection and arrangement are the suction conditions. The conventional suction geometry is not efficient for higher capacity of pump and thus reduced discharge on the delivery side. Intake manifold is being designed for this work. The previous configuration would be studied using CFD techniques while pursuing the objective of arriving at the most efficient geometry for the given application.
\end{abstract}

Key Wors: centrifugal pump, discharge, $C F D$

\section{INTRODUCTION}

Suction or inlet condition is an important factor of pump hydraulic system design. Due to cavitations, vortices, and prime losses, no proper allowances may occur. Pressure which is created by pump is lowered at the suction nozzle which induces the fluid to enter through inlet piping.

Less liquid being handled if any design that slow down the efficient transport of this liquid. In some cases Physical damage or crackers to the pump or any other part of pump is because of poor performance and bad designs of pump.

The study of pump suction system configuration is classified into two parts: (1) suction piping and (2) suction source. For properly design an efficient system, critical consideration should be given to suction piping and suction source. This study deals with pump suction system configuration and is applicable to all types of pumps, and successful operation and useful life of every pump can be so dependent on a properly designed and thought-out suction arrangement.

Relation of pipe and pipe fittings, quantity, and their location to the pump suction nozzle are help for proper suction piping design and installation consideration. the geometry of the source and the relative location of the suction entrance point to source enclosure boundaries, suction liquid surface, and other suction entrance points is include in Suction source design factors. This study deals with pump suction system configuration and is applicable to all types of pumps, and successful operation and useful life of every pump can be so dependent on a properly designed and thought-out suction arrangement.

\section{LITERATURE REVIEW}

1. R. Castilla a, P.J. Gamez-Montero a, N. Ert “ urk b, A. Vernet b, M. Coussirat c, E. Codina Analyzed in this paper. the flow in the suction chamber of an external gear pump is numerically. The present work is aimed at establishing a numerical procedure for an accurate computer simulation of the flow inside a gear pump. A new strategy for the simulation of flow in a gear pump with a commercial CFD code has been presented. In this strategy, an ALE formulation with mesh deforming-remeshing feature is combined with mesh replacement in order to avoid severely skewed meshes.

2. Dipti Prasad Mishra, Sukanta K Dash their present investigation predicts the suction flow rate from the atmosphere through the louvers of a funnel (used in naval and merchant ships) when the high velocity exhaust comes out from a nozzle or a set of nozzles placed inside the funnel. The work reported in this paper is a complete numerical investigation of parametric study of air suction rate through the louvers of a cylindrical funnel. Throughout the entire CFD analysis the funnel has been considered to be cylindrical in shape.

3. In the article, "Hydraulic design considerations for pump suction piping," discussed some problems which they can create.

4. Sadek Z. Kassab a, Hamdy A. Kandil a, Hassan A. Warda a, Wael H. Ahmed their objective of the present study is to evaluate the performance of a pump under predetermined operating conditions and to optimize the related factors. For this reason, an air-lift pump was designed and tested. Experiments were performed for submergence ratios, and risers of different lengths with different air injection pressures. 


\section{PROBLEM STATEMENT}

The one of the most important function of a pump suction system is to supply an imaginative, evenly distributed flow to the pump. Pump suction system should not support the external introduction or internal creation of compressible flow elements, and the intake configuration is a single pipe, an open sump, or a river otherwise this is harmful. Hydraulic disturbances that eventual destructive random frequency vibrations can cause because of improper design of the suction piping or inadequate pipe support exterior to the pump. Internal pump have some problems such as bearing failure, erosion, corrosion, seal failures, excessive noise, and excessive vibration can many times be rooted to source outside the pump itself and in the connected piping. Often times the trouble originate from poor suction conditions and piping practices that encourage unbalanced hydraulic flow. Hydraulic balance on pump rotating elements is maintained by the hydraulic stability. The direct connection of any type of pipe fitting to the pump suction nozzle should be avoided if at all possible. Pipe fittings cause rough flow patterns. In single end suction pump types, unequal liquid introduction to the impeller eye causes due to unbalanced flow axial to the pump . Because of thrust bearing wear is unbalanced, bearing life is reduced, and premature seal failure are increases. Direct connection of elbows should always be neglected. In double suction pumps, if directly connected elbows cannot be neglected, they should be installed such that the elbows are in a plane perpendicular to the pump shaft.

\section{OBJECTIVES}

- Identify the problem areas by studying the existing system

- Document the challenges to be addressed for enhancing the effectiveness of the pump

- Consider redesign of the suction end of the Pump through a provision of multiple intake for the water

- Analyze the multi-intake manifold design using CAE software, especially in the CFD domain

- Study the Test report shared by the Sponsoring Company

- Recommend the best alternative design for the suction side of the pumping system

- Reduce differential pressure losses in the flow

- Pump intake structure to ensure smooth and efficient flow distribution to one or more

pump suction inlets.

- Promote single phase flow while negating the vortices (air)

\section{DESIGN CRITERIA}

When flow is zero pump head will be highest with incessantly decreasing head as flow increases to insure steady operation of one or multiple pump in parallel, at all loadsPump will operate continuously without overheating or intolerable noises at minimum recirculation flow and at all loads without internal flashing.

Prerequisite will be made in pump design for expansion of

(a) Rotor and casing are relative to one another.

(b) Casing relative to the base.

(c) Pump rotor and shaft of the driver are relative to each other. (d) Outer and inner casing for double casing pumps.

The parts which rotates will be balanced statistically and dynamically for all speeds.

At all outputs axial as well as radial balance of the rotor will be provided by pump design.

One end of the pump shaft will be nearby for portable tachometer measurements.

Each pump will be provided with a pump reheat system so that when it is used as a supply it can be hot, ready for quick startup.

This is done by connecting orifice from the common discharge header to the pump discharge inside of the stop and check valve.

Then hot water can flow back through the pump and open inlet valve to the common suction header, thus keeping the pump at operating temperature.

Pump will be designed in that manner it will start safely from a cold start to full load in 60 seconds in an emergency, although it will normally be warmed before starting as described above.

\section{GENERAL PUMP}

\subsection{Experimentation}

The recommended design could be developed as a prototype for verification of the Mathematical or the Analytical model. This needs to be coupled with the required capacity of a suitable pump. For verification of the principle, a smaller capacity pump could be engaged for experimentation. Possibility for miniaturizing the setup can be explored for reasons of development time and the implied costs for development. Alternatively, the data secured from similar experiments done in the past by the Sponsoring Company could be benchmarked for Validation.

\section{CONCLUSION}

The data captured during experimentation would be compared with the result for experimentation. A good match or concurrence would indicate a strong basis for validation of the work. Appropriate correction factors needs to be considered while making the comparison due to effects of the environment or the variation in the physical setup or the condition of experiment.

\section{REFERENCES}

[1]. "Trouble shooting Process Operations", $4^{\text {th }}$ edition Norman Lieberman and pennwell books,

[2]. "Centrifugal pumps operation at off-design conditions", Chemical Processing Igor Karassik consulting engineer, Stefan Berten.

[3]. "Understanding NPSH for Pumps", Technical Publishing co, Travis Glover,igor j. karassik

[4]. "Centrifugal Pumps for General Refinery Services", Refining Department.

[5]. "Controlling Centrifugal Pumps", Hydrocarbon Processing, Walter Driedger

[6]. "Don't Run Centrifugal Pumps off the Right Side of the Curve", Mike Sondalini 
[7]. "Pump Handbook" , Third Edition , Igor Karassik, Joseph and Charles Heald

[8]. Numerical simulation of turbulent flow in the suction chamber of a gear pump using deforming mesh and mesh replacement by R. Castilla, P. Gamez-Montero a, N. Ert urk b, A. Vernet b, M. Coussirat c, E. Codina

[9]. Numerical investigation of air suction through the louvers of a funnel due to high velocity air jet - by Dipti Mishra

[10]. Hydraulic Design considerations for pump suction piping Part II by W.C. Krutxsch

[11]. Air-lift pumps characteristics under two-phase flow conditions by Sadek Z. Kassab a, Hamdy A.

\section{BIOGRAPHIES}

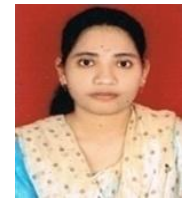

Ms. Vibha Pode received the B.E. degree in Mechanical Engineering from Government college of engineering Chandrapur in the year 2011. Currently pursuing M.E (Heat Power) at Dr. D. Y. Patil School of Engineering Academy. Working as an Lecturer at Dr. D. Y. Patil Institute of Engineering and Technology, AmbiTalegaon, Pune.

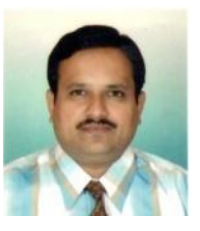

Prof.Shylesha Channapattana Received M.E in Mechanical Engineering (Heat Power) in 2005. Currently pursuing Ph.D. Administrative experience as Head of Section (Ibra College of Technology, Oman).

Five year teaching experience in abroad 